\title{
Morphological and Biochemical Parameters of Pigs' Blood with Enzootic Pneumonia
}

\author{
Artur Tazayan¹, Timur Tambiev¹, and Tatiana Babkina² \\ ${ }^{1}$ Department of Parasitology, Veterinary Sanitary Expertise and Epizootology, Don State Agrarian \\ University, Persianovsky, Russia \\ ${ }^{2}$ Department of Therapy and Propaedeutics, Don State Agrarian University, Persianovsky, Russia \\ ORCID: \\ Artur Tazayan: $h$ ttp://orcid.org/0000-0002-3476-6421 \\ Timur Tambiev: http://orcid.org/0000-0003-1561-231X
}

\section{Abstract}

One of the most common diseases of pigs in large pig enterprises is enzootic pneumonia. The main etiological agent causing enzootic pneumonia is Mycoplasma hyopneumoniae. Mycoplasmas have minimal virulence, but they increase the susceptibility of pigs to secondary infections. In association with other microorganisms, Mycoplasma hyopneumoniae enhances its pathogenic effect, which makes the

Corresponding Author:

Artur Tazayan

arthyr_61@mail.ru

Published: 5 April 2021

Publishing services provided by

Knowledge E

(c) Artur Tazayan et al. This article is distributed under the terms of the

Attribution License, which

permits unrestricted use and redistribution provided that the original author and source are credited.

Selection and Peer-review under the responsibility of the DonAgro Conference Committee. course of the disease more severe, often leading to the death of animals. Blood tests were performed to study the changes in morphological and biochemical parameters during the development of infection caused by Mycoplasma hyopneumoniae. Experimental groups of animals were formed, consisting of healthy as well as infected and ill pigs of different ages (2,3, and 4 months), in which the pathogen M. hyopneumoniae was detected by polymerase chain reaction. The following hematological changes were revealed in the piglets suffering from respiratory mycoplasmosis: erythropenia, leukopenia, increased blood sedimentation rate (BSR), hypoproteinemia, hypoalbuminemia, increased activity of alanine aminotransferase and alkaline phosphatase, increased urea, and hyperglycemia.

Keywords: pigs breeding; pneumonia; biochemical parameters; morphological parameters

\section{Introduction}

Infectious respiratory diseases of pigs are widespread in almost all countries of the world with developed pig farming. One of the most frequently reported diseases of this group is enzootic pneumonia of pigs [1, 2].

Enzootic pneumonia is a contagious (infectious) disease of the respiratory system of pigs, which is characterized by a chronic course, lobular serous-catarrh pneumonia, fever, dry cough, growth retardation and development of ill animals, high morbidity and relatively low mortality [3-4] 
The main etiological agent causing enzootic pneumonia is Mycoplasma hyopneumoniae. Mycoplasmas themselves have minimal virulence, but they increase the susceptibility of pigs to secondary infections. In association with other microorganisms, Mycoplasma hyopneumoniae enhances its pathogenic effect, which makes the course of the disease more severe, often leading to the death of animals [5-7, 2]

This infectious pathology causes enormous economic damage to many pig farms due to mortality, growth and development retardation, loss of breeding qualities of piglets, low feed conversion, as well as the cost of medical and preventive measures [8-10]

Especially often enzootic pneumonia is recorded in large pig-breeding complexes with a system of continuous year-round farrowing and a concentration of a huge number of livestock in a limited production area [11]

Due to the absence of typical symptoms of enzootic pneumonia, its occurrence in association with other infections, the diagnosis of this pathology is very difficult. In literary sources, there is little information on the characteristics of the course of the disease. There is practically no data on the morphological composition and biochemical changes in this disease, especially in groups of different ages [2, 5]

\section{Methods and Equipment}

The research was carried out at the Department of Parasitology, Veterinary Sanitary Expertise and Epizootology of Don State Agrarian University, at various pig farms in Rostov Region and Krasnodar Territory in Rostov Regional Veterinary Laboratory, Rostovon-Don. At the same time, the groups of animals were formed, consisting of clinically healthy (control group), as well as pigs with enzootic pneumonia of various ages (2, 3 , and 4 months) and with various forms of the disease (with subclinical course I experimental group and the clinical manifestation of the disease - II experimental group). In total, 180 young pigs were involved in the experiment, 20 in each group.

The diagnosis of enzootic pneumonia in pigs was made based on the detection of the pathogen genome (Mycoplasma Hyopneumoniae) in the blood by the method of polymerase chain reaction. The presence of specific antibodies to the causative agent of respiratory mycoplasmosis in the blood serum of animals by ELISA was also determined.

Laboratory studies included hematological and biochemical blood tests performed on a Mindray BC-2300 semi-automatic hematological analyzer. Biochemical studies were performed on a Sinnowa BS-3000P semi-automatic biochemical analyzer, using Deacon DDS reagents. 


\section{Results}

According to the results of hematological studies, it was found that with a general blood test in piglets of 2 months old, there were no statistically significant differences in the red blood indices in the animals of the control and first experimental groups. Thus, in the control and first experimental groups of animals, the amount of hemoglobin and the number of red blood cells was $105.8-9.96 \mathrm{~g} / \mathrm{l}, 6,51 \pm 1,168 \times 10^{12} / \mathrm{l}$, and $97.2-9.11 \mathrm{~g} / \mathrm{l}$, $5.91 \pm 1.49 \times 10^{12} \times 1012 / /$, respectively. Whereas in the second experimental group these indicators amounted to $90.01 \pm 11.21 \mathrm{~g} / \mathrm{l}, 4.09 \pm 1.27 \times 10^{12} / \mathrm{l}$. The hematocrit in animals in the control group was lower than in animals in the experimental groups by 33.5 and $64.1 \%$, respectively, in the first and second groups.

Thus, there is a decrease in the number of red blood cells in the first experimental group by $10.3 \%$, in the second experimental group by $41.3 \%$, hemoglobin by $8.3 \%$ and $40.7 \%$, respectively, compared to the control group (Table 1).

TABLE 1: Morphological indicators of blood in pigs with enzootic pneumonia at the age of 2 months. ( $N=$ 60)

\begin{tabular}{l|c|c|c|}
\hline Indicators & Control group & \multicolumn{2}{c|}{ Experimental groups } \\
\hline Red blood cells, $\times 10^{12} / /$ & $6.51 \pm 1.16$ & $I$ & II \\
\hline Hemoglobin, g/l & $105.8 \pm 9.96$ & $5.91 \pm 1.49$ & $4.09 \pm 1.27^{*}$ \\
\hline Hematocrit, \% & $0.41 \pm 0.02$ & $97.2 \pm 9.11$ & $90.01 \pm 1.21^{*}$ \\
\hline BSR, $\mathrm{mm} / \mathrm{h}$ & $2.13 \pm 0.93$ & $0.36 \pm 0.03$ & $0.31 \pm 0.03$ \\
\hline
\end{tabular}

Legend: $P<0.05^{*} ; \mathrm{P}<0.01^{* *}-\mathrm{P}<0.001^{* * *}$

The same trend was noted in the study of red blood in 2 months piglets, it also remains at the age of 3 months (Table 2).

TABLE 2: Morphological indicators of blood in pigs with enzootic pneumonia at the age of 3 months. $(\mathrm{N}=$ 60

\begin{tabular}{l|c|}
\hline Indicators & Control group \\
\hline Red blood cells, $\times 10^{12} / /$ & $6.97 \pm 0.42$ \\
\hline Hemoglobin, $\mathrm{g} / \mathrm{l}$ & $109.64 \pm 7.21$ \\
\hline Hematocrit, \% & $0.43 \pm 0.01$ \\
\hline BSR, $\mathrm{mm} / \mathrm{h}$ & $2.2 \pm 0.95$ \\
\hline
\end{tabular}

\begin{tabular}{|c|c|}
\hline \multicolumn{2}{|c|}{ Experimental groups } \\
\hline$I$ & \multicolumn{1}{|l|}{} \\
\hline $5.49 \pm 1.27$ & $3.91 \pm 1.23^{* *}$ \\
\hline $103.70 \pm 8.37$ & $88.55 \pm 16.26^{* *}$ \\
\hline $0.41 \pm 0.06$ & $0.27 \pm 0.05^{* *}$ \\
\hline $2.84 \pm 1.10$ & $10.2 \pm 5.09^{* * *}$ \\
\hline
\end{tabular}

Legend: $\mathrm{P}<0.05^{*} ; \mathrm{P}<0.01^{* *}-\mathrm{P}<0.001^{* * *}$

There are no statistically significant differences between the indicators of red blood in the control and the first experimental groups. Statistically significant differences were obtained only in the study of hematocrit, which was $4.7 \%$ higher in the control group. 
However, the changes in the indicators of red blood in the second experimental group were noted. Thus, the amount of hemoglobin and the number of red blood cells was 88.55-16.26 g/l, 3.91-1.23 × 1012/l, which is $44.9 \%$ lower than in the control and 33.7 $\%$ lower than in the first experimental group, respectively.

BSR indices in animals of the control and the first experimental groups did not statistically differ. Whereas in animals of the second experimental group, BSR turned out to be increased $-10.2-5.09 \mathrm{~mm} / \mathrm{h}$, which is 4.6 times higher than in the control and 3.5 times higher than in the first experimental group.

At the age of 4 months, the changes in red blood cells were exacerbated in both experimental groups (Table 3), since there were already statistically significant differences in the control and first experimental groups, the amount of hemoglobin and the number of red blood cells was $110-9.31 \mathrm{~g} / \mathrm{l}, 6,93 \pm 0.87 \times 10^{12} / /$ and $97.3 \pm 12.21$ $\mathrm{g} / \mathrm{l}, 4.3 \pm 0.95 \times 10^{12} / \mathrm{l}$, respectively. In the second experimental group, the amount of hemoglobin and the number of red blood cells was $86 \pm 11.21 \mathrm{~g} / /$ and $3.27 \pm 0.81 \times 10^{12} / /$, which is 21.9, 11.4 and 50.0, $24 \%$ lower than in the control and the first experimental group, respectively.

TABLE 3: Morphological indicators of blood in pigs with enzootic pneumonia at the age of 4 months. $(\mathrm{N}=$ 60)

\begin{tabular}{l|c|c|c|}
\hline Indicators & Control group & \multicolumn{2}{c}{ Experimental groups } \\
\hline Red blood cells, $\times 10^{12} / /$ & $6.93 \pm 0.87$ & $I$ & \multicolumn{1}{|l}{} \\
\hline Hemoglobin, g/l & $110 \pm 9.31$ & $4.3 \pm 0.95^{* *}$ & $3.27 \pm 0.81^{* * *}$ \\
\hline Hematocrit, \% & $0.44 \pm 0.09$ & $97.3 \pm 12.21^{*}$ & $86 \pm 11.21^{* *}$ \\
\hline BSR, mm/h & $3.04 \pm 3.20$ & $8.30 \pm 2.10^{* * *}$ & $13.2 \pm 3.14^{* * *}$ \\
\hline
\end{tabular}

Legend: $P<0.05^{*} ; \mathrm{P}<0.01^{* *}-\mathrm{P}<0.001^{* * *}$

The overall dynamics in the age aspect of the indicators of red blood in pigs with enzootic pneumonia caused by M. hyopneumoniae is shown in table 4 .

Thus, as animals grow, red blood gradually increase, so red blood cells in the control group increase from 2 months up to 4 months of age from $6.51 \pm 1.168 \times 10^{12} / /$ to $6.93 \pm 0.87 \times 10^{12} / \mathrm{l}$, hemoglobin from $105.8 \pm 9.96 \mathrm{~g} / \mathrm{l}$ to $110 \pm 9.31 \mathrm{~g} / \mathrm{l}$. When pigs have enzootic pneumonia caused by M. hyopneumoniae, a physiological age-related increase in red blood does not occur, but on the contrary, a decrease is noted. Thus, in the first experimental group, the number of red blood cells and the amount of hemoglobin decrease from $5.91 \pm 1.49 \times 10^{12} / \mathrm{I}$ and $97.2 \pm 9,11 / \mathrm{I}$ to $4.3 \pm 0.95 \times 10^{12} / \mathrm{I}$ and $97.3 \pm 12.21 \mathrm{~g} / \mathrm{l}$, respectively, and in the second experimental group from 4,09 \pm 1.27 $\times 10^{12} / \mathrm{l}$ and $90.01 \pm 11.21 \mathrm{~g} / \mathrm{l}$ to $3.27 \pm 0.81 \times 10^{12} / \mathrm{l}$ and $86 \pm 11.21 \mathrm{~g} / \mathrm{l}$, respectively. 
TABLE 4: Red blood indicators of experimental groups in the age aspect $(N=60)$

\begin{tabular}{l|c|c|c}
\hline Indicators & \multicolumn{3}{c}{ Age } \\
& 2 months & 3 months & 4 months \\
\hline Red blood cells, $\times 10^{12} / /$ & \multicolumn{2}{c|}{ Control group } & \\
\hline Hemoglobin, g/l & $105.8 \pm 1.16$ & $6.97 \pm 0.42$ & $6.93 \pm 0.87$ \\
\hline Hematocrit, \% & $0.41 \pm 0.02$ & $109.64 \pm 7.21$ & $110 \pm 9.31$ \\
\hline BSR, mm/h & $2.13 \pm 0.93$ & $0.43 \pm 0.01$ & $0.44 \pm 0.09$ \\
\hline Red blood cells, $\times 10^{12} / /$ & $5.91 \pm 1.49$ & $2.2 \pm 0.95$ & $3.04 \pm 3.20$ \\
\hline Hemoglobin, g/l & $97.2 \pm 9.11$ & $5.49 \pm 1.27$ & \\
\hline Hematocrit, \% & $0.36 \pm 0.03$ & $103.70 \pm 8.37$ & $4.3 \pm 0.95^{* *}$ \\
\hline BSR, mm/h & $3.20 \pm 1.84^{*}$ & $0.41 \pm 0.06$ & $97.3 \pm 12.21^{*}$ \\
\hline Red blood cells, $\times 10^{12} / /$ & $4.09 \pm 1.27^{*}$ & $2.84 \pm 1.10$ & $0.36 \pm 0.05^{*}$ \\
\hline Hemoglobin, g/l & $90.01 \pm 1.21^{*}$ & $88.55 \pm 16.26^{* *}$ & $8.30 \pm 2.10^{* * *}$ \\
\hline Hematocrit, \% & $0.31 \pm 0.03$ & $0.27 \pm 0.05^{* *}$ & $86 \pm 11.21^{* *}$ \\
\hline BSR, mm/h & $5.93 \pm 1.01^{* * *}$ & $10.2 \pm 5.09^{* * *}$ & $0.28 \pm 0.10^{* * *}$ \\
\hline
\end{tabular}

Legend: $P<0.05^{*} ; \mathrm{P}<0.01^{* *}-\mathrm{P}<0.001^{* * *}$

In addition to indicators of red blood, we determined indicators of white blood and derived leukocyte formulas in pigs of experimental groups. The level of leukocytes in pigs at the age of 2 months of the control group was $12.6 \pm 0.8 \times 109 \mathrm{~g} / \mathrm{l}$ (table 5).

TABLE 5: Blood layogram in pigs with enzootic pneumonia at the age of 2 months. $(N=60)$

\begin{tabular}{l|c|c|c|}
\hline Indicators & Control group & \multicolumn{2}{c|}{ Experimental groups } \\
\hline Leucocytes, $\times 10^{9} \mathrm{~g} / \mathrm{l}$ & $12.6 \pm 0.80$ & \multicolumn{1}{c|}{ II } \\
\hline Eosinophiles, \% & $3.4 \pm 0.99$ & $9.70 \pm 2.33^{*}$ & $6.20 \pm 2.25^{* *}$ \\
\hline Immature, \% & - & $1.4 \pm 0.69^{* *}$ & $0.3 \pm 0.21^{* * *}$ \\
\hline Banded neutrophile, \% & $9.6 \pm 0.56$ & - & $2.2 \pm 0.43^{* * *}$ \\
\hline Segmentonuclear & $37.6 \pm 11.12$ & $25.38 \pm 2.87^{* * *}$ & $27.4 \pm 3.4^{* * *}$ \\
\hline neutrophils, \% & & $47.22 \pm 12.12^{*}$ & $52.1 \pm 12.15^{* *}$ \\
\hline Lymphocytes, \% & $46.9 \pm 3.34$ & $24.4 \pm 8.47^{* *}$ & $17.3 \pm 2.3^{* * *}$ \\
\hline Monocytes, \% & $2.5 \pm 1.23$ & $1.6 \pm 0.31^{*}$ & $0.7 \pm 0.31^{* *}$ \\
\hline
\end{tabular}

Legend: $\mathrm{P}<0.05^{*} ; \mathrm{P}<0.01^{* *}-\mathrm{P}<0.001^{* * *}$

In pigs of the first experimental group, leukocytes amounted to $9.70 \pm 3.33 \times 109 \mathrm{~g} / \mathrm{l}$, and in the group of animals of the second experimental group $6.20 \pm 2.33 \times 109 \mathrm{~g} / \mathrm{l}$, which is 19 and $56 \%$ less than in animals of the control groups.

The number of eosinophils in pigs in the control group was 3.4-0.99\%. The same indicator in the group of animals of the first experimental group amounted to 1.4-0.69 
$\%$. In the group of animals of the second experimental group, $0.3-0.21 \%$, this is 55 and $91.2 \%$ less than in animals of the control group.

The number of stab neutrophils in pigs in the control group was $9.6-0.56 \%$. The same indicator in the first experimental group was $25.38-2.87 \%$. In animals of the second experimental group, it was $27.4-3.4 \%$, which is $163.5 \%$ and $185.4 \%$ more than in animals of the control group.

The number of segmented neutrophiles in pigs in the control group was 37.6-11.12 $\%$. The same indicator in the first experimental group was $47.22-12.12 \%$. In animals of the second experimental group, it was $52.1-12.5 \%$, which is $31.3 \%$ and $44.8 \%$ more than in animals of the control group.

The number of lymphocytes in animals of the control group was 46.9-3.34\%. The same indicator in the first experimental group was $24.4-8.47 \%$, and in animals of the second experimental group was $17.3-2.3 \%$, which is $48.9 \%$ and $66.04 \%$ less, respectively, than animals of the control group.

The number of monocytes in animals of the control group was $2.5-1.23 \%$. The same indicator in the first experimental group was $1.6 \pm 0.31 \%$, and in animals of the second experimental group it was $0.7 \pm 0.31 \%$, which is $36.2 \%$ and $72.04 \%$ less, respectively, than animals of the control group.

Thus, with increasing age in piglets with enzootic pneumonia caused by $M$. hyopneumoniae, the development of leukopenia and eosinopenia is noted. However, the decrease in the number of lymphocytes is especially pronounced, their percentage reflected a four-fold decrease in the second experimental group in relation to healthy animals, but given the increasing leukopenia, lymphopenia is even more pronounced.

The level of leukocytes in pigs of 3 months of the control group was $13.96 \pm 1.37 \times 10^{9} \mathrm{~g} / \mathrm{l}$. The same indicator in pigs of the first experimental group was $11.19 \pm 3.18 \times 10^{9} \mathrm{~g} / \mathrm{l}$, and in the group of animals of the second experimental group it was $7.33 \pm 1.55 \times 10^{9} \mathrm{~g} / \mathrm{l}$, which is $19.84 \%$ and $52.51 \%$ less than in animals of the control group (table 6).

The number of eosinophils in pigs in the control group was $4.36-0.56 \%$. The same indicator in the group of animals of the first experimental group was $2.08-0.7 \%$. In the group of animals of the second experimental group, 1.29-0.11\%, this is 52.29 and 70.41 $\%$ less than in animals of the control group.

The number of banded neutrophiles in pigs in the control group was 10.49-0.8 $\%$. The same indicator in the first experimental group was 19.14-3.16\%. In animals of the second experimental group it was $19.01-2.28 \%$, which is $82.46 \%$ and 81.22 $\%$ more than in animals of the control group. Despite the fact that the percentage of 
banded neutrophiles in the first and second experimental groups turned out to be almost the same, more pronounced leukopenia in the second experimental group causes a decrease in the number of stab banded neutrophiles in the second experimental group, compared to the control and the first experimental.

TABLE 6: Blood layogram in pigs with enzootic pneumonia at the age of 3 months. $(N=60)$

\begin{tabular}{l|c|}
\hline Indicators & Control group \\
\hline Leucocytes, $\mathrm{x} 10^{9} \mathrm{~g} / \mathrm{l}$ & $13.96 \pm 1.37$ \\
\hline Eosinophiles, \% & $4.36 \pm 0.56$ \\
\hline $\begin{array}{l}\text { Immature, \% } \\
\text { Banded neutrophile, \% }\end{array}$ & - \\
\hline $\begin{array}{l}\text { Segmentonuclear } \\
\text { neutrophils, \% }\end{array}$ & $33.26 \pm 11.01$ \\
\hline Lymphocytes, \% & $50.85 \pm 9.44$ \\
\hline Monocytes, \% & $4.06 \pm 1.65$ \\
\hline
\end{tabular}

\begin{tabular}{|c|c|}
\hline \multicolumn{2}{|c|}{ Experimental groups } \\
\hline$I$ & \multicolumn{1}{|c|}{$7.33 \pm 1.55^{* *}$} \\
\hline $11.19 \pm 3.18$ & $1.29 \pm 0.11^{* * *}$ \\
\hline $2.08 \pm 0.7^{* *}$ & $2.18 \pm 0.44^{* * *}$ \\
\hline- & $19.01 \pm 2.28^{* *}$ \\
\hline $19.14 \pm 3.16^{* *}$ & $50.09 \pm 5.65^{* *}$ \\
\hline $44.65 \pm 6.25^{*}$ & \\
\hline $31.85 \pm 1.34^{* *}$ & $25.94 \pm 1.88^{* * *}$ \\
\hline $2.28 \pm 0.53^{* *}$ & $1.49 \pm 0.24^{* * *}$ \\
\hline
\end{tabular}

Legend: $\mathrm{P}<0.05^{*} ; \mathrm{P}<0.01^{* *}-\mathrm{P}<0.001^{* * *}$

The number of segmentonuclear neutrophiles in pigs in the control group was 33.26$11.01 \%$. The same indicator in the first experimental group was 44.65-6.25\%. In animals of the second experimental group it was 50.85-5.65\%, which is $34.25 \%$ and $50.6 \%$ more than in animals of the control group. Despite the relative neutrophilia in mycoplasmosis, absolute neutropenia develops due to severe leukopenia.

The number of lymphocytes in animals of the control group was $50.09 \pm 9.44 \%$. The same indicator in the first experimental group was $31.85-1.34 \%$, and in animals of the second experimental group it was $25.94-1.88 \%$, which is $37.9 \%$ and $50.19 \%$ less, respectively, than animals of the control group.

The number of monocytes in animals of the control group was $4.06-1.65 \%$. The same indicator in the first experimental group was $2,28 \pm 0,53 \%$, and in animals of the second experimental group it was $1,49 \pm 0,24 \%$, which is $43.84 \%$ and $63.3 \%$ less, respectively, than animals of the control group.

Thus, as pigs with enzootic pneumonia caused by $M$. hyopneumoniae grow, the development of leukopenia and eosinopenia is noted. However, the decrease in the absolute number of lymphocytes is especially pronounced, their percentage reflected a fourfold decrease in the second experimental group in relation to healthy animals, but given the increasing leukopenia, lymphopenia is even more pronounced. Despite the relative neutrophilia in the experimental groups, due to severe leukopenia, neutropenia is noted. 
The leukocyte level in pigs of 4 months old of the control group, was $16.04 \pm 2.39$ $\times 109 \mathrm{~g} / \mathrm{l}$. The same indicator in pigs of the first experimental group was $11.98 \pm 4.37$ $\times 109 \mathrm{~g} / \mathrm{l}$, and in the group of animals of the second experimental group $9.15 \pm 1.33 \times$ $109 \mathrm{~g} / \mathrm{l}$, which is 25.31 and 42.96 \% less than in animals of the control group (table 7).

TABLE 7: Blood layogram in pigs with enzootic pneumonia at the age of 4 months. $(N=60)$

\begin{tabular}{l|c|c|c|}
\hline Indicators & Control group & \multicolumn{2}{c|}{ Experimental groups } \\
\hline Leucocytes, $\times 10^{9} \mathrm{~g} / \mathrm{I}$ & $16.04 \pm 2.39$ & \multicolumn{1}{|c|}{ II } \\
\hline Eosinophiles, \% & $5.05 \pm 1.02$ & $3.28 \pm 1.44$ & $9.15 \pm 1.33^{* *}$ \\
\hline Immature, \% & 0 & $3.17 \pm 0.21^{* * *}$ & $2.48 \pm 0.46$ \\
\hline Banded neutrophile, \% & $5.25 \pm 0.98$ & $12.33 \pm 2.18^{* *}$ & $6.07 \pm 0.26^{* * *}$ \\
\hline Segmentonuclear & $31.10 \pm 9.24$ & $45.84 \pm 3.18^{*}$ & $16.93 \pm 3.07^{* * *}$ \\
\hline neutrophils, \% & & & $44.79 \pm 3.17^{*}$ \\
\hline Lymphocytes, \% & $54.05 \pm 9.47$ & $31.92 \pm 2.42^{* *}$ & $27.26 \pm 1.39^{* *}$ \\
\hline Monocytes, \% & $4.55 \pm 1.38$ & $3.47 \pm 0.21$ & $2.47 \pm 0.24^{* *}$ \\
\hline
\end{tabular}

Legend: $\mathrm{P}<0.05^{*} ; \mathrm{P}<0.01^{* *}-\mathrm{P}<0.001^{* * *}$

The number of eosinophils in pigs in the control group was $5.05 \pm 1.02 \%$. While the same indicator among animals of the first experimental group was $3.28 \pm 1.44 \%$, among piglets of the second experimental group the number of eosinophils was 2.48 $\pm 0.46 \%$, which is 35.05 and $50.89 \%$ less than in animals of the control group.

The number of banded neutrophiles in pigs in the control group was $5.25 \pm 0.98$ $\%$. The same indicator in the first experimental group was $12.33 \pm 2.18 \%$. In animals of the second experimental group it was $16.93 \pm 3.07 \%$, which is 134.86 and 222.48 $\%$ more than in animals of the control group. Despite the fact that the percentage of stab neutrophiles in the first and second experimental groups turned out to be almost the same, more pronounced leukopenia in the second experimental group causes a decrease in the number of banded neutrophiles in the second experimental group, compared to the control and the first experimental groups.

The number of segmented neutrophiles in pigs in the control group was $31.1 \pm 9.24$ $\%$. The same indicator in the first experimental group was $45.84 \pm 3.18 \%$. In animals of the second experimental group it was $44.79 \pm 3.17 \%$, which is 47.4 and $44.02 \%$ more than in animals of the control group. Despite relative neutrophilia, neutropenia develops with respiratory mycoplasmosis due to severe leukopenia.

The number of lymphocytes in animals of the control group was $54.05 \pm 9.47 \%$. The same indicator in the first experimental group was $31.92 \pm 2.42 \%$, and in animals of the second experimental group it was $27.26 \pm 1.39 \%$, which is 48.2 and $50.2 \%$ less, respectively, than animals of the control group. 
The number of monocytes in animals of the control group was $4.55 \pm 1.38 \%$. The same indicator in the first experimental group was $3.47 \pm 0.21 \%$, and in animals of the second experimental group it was $2.47 \pm 0.24 \%$, which is 41.73 and $50.8 \%$ less, respectively, than animals of the control group.

Thus, in pigs with enzootic pneumonia caused by $M$. hyopneumoniae, leukopenia and eosinopenia are observed. However, the decrease in the number of lymphocytes is especially pronounced, their percentage showed a four-fold decrease in the second experimental group in relation to healthy animals, but given the increasing leukopenia, lymphopenia is even more pronounced. Despite the relative neutrophilia in the experimental groups, due to severe leukopenia, neutropenia is noted.

Thus, in pigs at 4 months of age, the general trends in the dynamics of the leukoformula remained the same, leukopenia, relative neutrophilia with neutropenia, and severe and relative lymphopenia were noted.

The results of biochemical blood tests in pigs with enzootic pneumonia caused by M. hyopneumoniae at the age of 2 months are presented in table 8.

The experiments showed that the changes in blood biochemical parameters depend on the severity of clinical signs in pig enzootic pneumonia. However, there are significant differences.

As it can be seen from table 8 , in animals of the second experimental group, compared to the pigs of the control and the first experimental group, statistically significant hypoproteinemia and hypoalbuminemia were observed, while the level of globulins did not change significantly, which explains the sharp decrease in the albuminglobulin ratio.

TABLE 8: Biochemical indicators of blood in pigs with enzootic pneumonia at the age of 2 months $(N=60)$

Indicators
Total protein, $\mathrm{g} / \mathrm{l}$
Albumin, $\mathrm{g} / \mathrm{l}$
Globulin, $\mathrm{g} / \mathrm{l}$
Alanine aminotransferase,
Unit/L
Alkaline phosphatase, E/L
Urea, $\mathrm{mmol} / \mathrm{L}$
Bilirubin, $\mathrm{Hmol} / \mathrm{L}$
Glucose, $\mathrm{mmol} / \mathrm{L}$

\begin{tabular}{|l|}
\hline Control group \\
\hline $67.53 \pm 2.19$ \\
\hline $32.75 \pm 3.2$ \\
\hline $37.77 \pm 2.91$ \\
\hline $41.77 \pm 5.44$ \\
\hline $53.74 \pm 5.85$ \\
\hline $4.82 \pm 1.04$ \\
\hline $4.40 \pm 0.66$ \\
\hline $5.65 \pm 0.28$ \\
\hline
\end{tabular}

\begin{tabular}{|c|c|}
\hline \multicolumn{2}{|c|}{ Experimental groups } \\
\hline$I$ & \multicolumn{1}{|c|}{ I } \\
\hline $69.57 \pm 4.78$ & $58.03 \pm 3.23^{*}$ \\
\hline $32.57 \pm 2.47$ & $22.89 \pm 2.17^{*}$ \\
\hline $35.54 \pm 3.59$ & $40.09 \pm 3.71$ \\
\hline $83.36 \pm 10.3$ & $82.06 \pm 8.95$ \\
\hline $58.53 \pm 8.20$ & $68.64 \pm 5.44^{*}$ \\
\hline $6.11 \pm 1.27^{*}$ & $7.17 \pm 0.98^{*}$ \\
\hline $6.42 \pm 0.87$ & $6.85 \pm 1.13^{*}$ \\
\hline $6.46 \pm 0.20^{*}$ & $7.13 \pm 0.10^{*}$ \\
\hline
\end{tabular}

Legend: $\mathrm{P}<0.05^{*} ; \mathrm{P}<0.01^{* *}-\mathrm{P}<0.001^{* * *}$ 
Thus for animals of the control group, the activity of alanine aminotransferase in the blood serum is 41.77-5.44, while in the first and second experimental groups, respectively, these indicators were $83.36 \pm 10.3 ; 82.06 \pm 8.95 \mathrm{U} / \mathrm{L}$., which indicates the response of the liver to the inflammatory process.

The increase in alkaline phosphatase activity from 58.53-8.20 U/L in the I experimental group to $68.64-5.44 \mathrm{U} / \mathrm{L}$ in the II group, compared to the indices in the animals of the control group $53.74-5.85$ was $108.91 \%$ and $127.73 \%$, respectively.

The urea level in pigs of the first experimental group was $6.11-1.27 \mathrm{mmol} / \mathrm{L}$. The same indicator in the group of animals of the control group was 4.82-1.04 mmol/L. In animals of the II experimental group, this indicator is $7.21-0.99 \mathrm{mmol} / \mathrm{L}$, which is higher than in the control group. This suggests a negative effect of mycoplasmas on kidney function. The glucose level in pigs of the first experimental group was 6.46-0.20 $\mathrm{mmol} / \mathrm{L}$. In pigs, the control group was $4.82-0.28 \mathrm{mmol} / \mathrm{L}$. In the group of animals of the second experimental group it amounted to $7.13,10.10 \mathrm{mmol} / \mathrm{l}$, respectively, which also indicates the involvement of an increased glucose release into the pathological process of carbohydrate metabolism.

The level of bilirubin in experimental animals was within the limits of physiological fluctuations, which indicates an undisturbed pigment function of the liver. Although, compared to the control group in the experimental groups, insignificant changes of 6.42-0.87 and 6.85-1.13 were observed.

The results of biochemical blood tests in pigs at 3 months of age, with enzootic pneumonia caused by M. hyopneumoniae, are presented in table 9.

TABLE 9: Biochemical indicators of blood in pigs with enzootic pneumonia at the age of 3 months. $(N=60)$

Indicators
Total protein, g/l
Albumin, g/l
Globulin, g/l
Alanine
aminotransferase,
Unit/L
Alkaline phosphatase,
E/L
Urea, mmol/L
Bilirubin, $\mu \mathrm{mol} / \mathrm{L}$
Glucose, $\mathrm{mmol} / \mathrm{L}$

\begin{tabular}{|c|}
\hline Control group \\
\hline $63.36 \pm 3.79$ \\
\hline $27.86 \pm 3.9$ \\
\hline $36.04 \pm 8.83$ \\
\hline $95.20 \pm 13.66$ \\
\hline $75.44 \pm 12.96$ \\
\hline $6.05 \pm 1.09$ \\
\hline $6.36 \pm 1.08$ \\
\hline $4.78 \pm 0.10$ \\
\hline
\end{tabular}

\begin{tabular}{|c|c|}
\hline \multicolumn{2}{|c|}{ Experimental groups } \\
\hline$I$ & $\|$ \\
\hline $52.3 \pm 3.68^{*}$ & $49.1 \pm 3.75^{*}$ \\
\hline $23.50 \pm 2.42$ & $18.01 \pm 2.24^{*}$ \\
\hline $29.30 \pm 6.13$ & $31.28 \pm 6.2$ \\
\hline $103.5 \pm 8.58$ & $123.9 \pm 9.64^{*}$ \\
\hline $93.78 \pm 5.51^{*}$ & $166.22 \pm 6.38^{* * *}$ \\
\hline $7.27 \pm 0.85$ & $10.21 \pm 0.97^{*}$ \\
\hline $6.17 \pm 1.36$ & $4.05 \pm 1.32^{*}$ \\
\hline $4.84 \pm 0.10$ & $8.74 \pm 0.10^{* *}$ \\
\hline
\end{tabular}

Legend: $\mathrm{P}<0.05^{*} ; \mathrm{P}<0.01^{* *}-\mathrm{P}<0.001^{* * *}$ 
The experimental group I is characterized by the increase in the activity of alanine aminotransferase in blood serum, respectively, to $103.5 \pm 8.58 \mathrm{U} / \mathrm{L} ; 123.9 \pm 9.64 \mathrm{U} / \mathrm{L}$, whereas in the control group of animals these indicators were $95.20 \pm 13.66 \mathrm{U} / \mathrm{L}$.

The increase in the activity of alkaline phosphatase to $93.78-5.51 \mathrm{U} / \mathrm{L}$ in the experimental group I, to $166.22-6.38 \mathrm{U} / \mathrm{L}$ in the second experimental group, compared to the indices in the animals of the control group was 24.31 and $120.33 \%$ respectively.

The urea level in pigs of the first experimental group was $7.27-0.85 \mathrm{mmol} / \mathrm{L}$. The same indicator among the animals of the control group was $6.05-1.09 \mathrm{mmol} / \mathrm{L}$. In animals of the II experimental group, this indicator is 10,21 $\pm 0,97 \mathrm{mmol} / \mathrm{L}$, which is 20.17 and 68.76 $\%$ more in comparison with the animals of the control group. The glucose level in pigs of the first experimental group was $4,84 \pm 0,1 \mathrm{mmol} / \mathrm{L}$. In pigs of the control group was $4,78 \pm 0,1 \mathrm{mmol} / \mathrm{L}$. In the second experimental group it was $8.74 \mathrm{mmol} / \mathrm{l}$, respectively, which is 1.26 and $81.85 \%$ more than in animals of the control group.

As it can be seen from table 9, hypoproteinemia is aggravated, but in addition, in pigs with enzootic pneumonia caused by $M$. hyopneumoniae, hyperglycemia is quite pronounced, which is apparently associated with transient hypercorticosteroneemia, which is characteristic of all stress reactions. In addition, if the pigs of the first experimental group were characterized by a decrease in urea relative to the animals of the control group, then in animals of the second experimental group its increase to the upper limit of the norm is noted.

The results of biochemical blood tests in pigs at 4 months of age with enzootic pneumonia caused by $\mathrm{M}$. hyopneumoniae are presented in table 10.

TABLE 10: Biochemical indicators of blood in pigs with enzootic pneumonia at the age of 4 months. $(N=60)$

Indicators
Total protein, g/l
Albumin, g/l
Globulin, g/l
Alanine
aminotransferase,
Unit/L
Alkaline phosphatase,
E/L
Urea, mmol/L
Bilirubin, $\mu \mathrm{mol} / \mathrm{L}$
Glucose, $\mathrm{mmol} / \mathrm{L}$

\begin{tabular}{|c|}
\hline Control group \\
\hline $69.45 \pm 4.28$ \\
\hline $36.22 \pm 3.20$ \\
\hline $32.73 \pm 4.14$ \\
\hline $94.6 \pm 14.1$ \\
\hline $74.66 \pm 17.03$ \\
\hline $6.33 \pm 2.64$ \\
\hline $6.04 \pm 1.73$ \\
\hline $4.78 \pm 0.10$ \\
\hline
\end{tabular}

\begin{tabular}{|c|c|}
\hline \multicolumn{2}{|c|}{ Experimental groups } \\
\hline I & II \\
\hline $53.74 \pm 1.82$ & $48.6 \pm 1.97^{*}$ \\
\hline $23.95 \pm 1.71^{*}$ & $17.88 \pm 2.04^{* *}$ \\
\hline $30.6 \pm 3.88$ & $30.52 \pm 5.57$ \\
\hline $102.42 \pm 11.09$ & $123.81 \pm 11.58^{*}$ \\
\hline $93.54 \pm 12.77^{*}$ & $166.9 \pm 11.76^{* *}$ \\
\hline $7.43 \pm 1.18$ & $10.52 \pm 1.68^{*}$ \\
\hline $6.03 \pm 1.97$ & $4.02 \pm 1.87^{*}$ \\
\hline $4.89 \pm 0.10$ & $8.74 \pm 0.10^{* * *}$ \\
\hline
\end{tabular}

Legend: $\mathrm{P}<0.05^{*} ; \mathrm{P}<0.01^{* *}-\mathrm{P}<0.001^{* * *}$ 
The $1^{\text {st }}$ experimental group is characterized by the increase in the activity of serum alanine aminotransferase to $102.42 \pm 11.09 \mathrm{U} / \mathrm{L}$, respectively; $123.81 \pm 11.58 \mathrm{U} / \mathrm{L}$, whereas in the control group these indicators were $94.6 \pm 14.1 \mathrm{U} / \mathrm{L}$.

The increase in the activity of alkaline phosphatase to $93.54 \pm 12.77 \mathrm{U} / \mathrm{L}$ in the first experimental group, to $166.9-11.76 \mathrm{U} / \mathrm{L}$ in the second experimental group, relative to the indices in the animals of the control group was $25.29 \%$ and $123.55 \%$ respectively.

The urea level in pigs of the first experimental group was $7.43-1.18 \mathrm{mmol} / \mathrm{L}$. The same indicator in the group of animals of the control group was $6.33-2.64 \mathrm{mmol} / \mathrm{l}$. In animals of the experimental group II, this indicator is $10.52-1.68 \mathrm{mmol} / \mathrm{l}$, which is 17.38 and $66.19 \%$ more than in the animals of the control group. The glucose level in pigs, the first experimental group was $4.89 \pm 0.1 \mathrm{mmol} / \mathrm{L}$. In pigs, the control group was $4.78 \pm 0.1 \mathrm{mmol} / \mathrm{L}$. In the group of animals of the second experimental group it was $8.74 \pm 0.1 \mathrm{mmol} / \mathrm{L}$, respectively, which is 2.3 and $82.85 \%$ more than in animals of the control group.

The general trends in the development of hypoproteinemia, hypoalbuminemia and hypoglobulinemia in pigs with enzootic pneumonia caused by $M$. hyopneumoniae remain. Hyperglycemia develops, which fits into the theoretical aspects of the development of stress response. The level of alkaline phosphatase, alanine transferase and urea is increasing, which indicates impaired function not only of the lungs, but also of the liver, kidneys and other organs.

As animals grow from 2 months up to 4 months of age, red blood gradually increase by an average of $23.6 \%$. When pigs are infected with enzootic pneumonia caused by M. hyopneumoniae, there is no physiological increase in red blood, but, on the contrary, there is a decrease in the studied indices by an average of $14.9 \%$.

The experiments showed that changes in blood biochemical parameters in pigs depend on the severity of symptoms of enzootic pneumonia caused by M. hyopneumoniae.

\section{Conclusion}

1. In piglets with a subclinical form of enzootic pneumonia, the following hematological parameters were observed: erythropenia up to $4.3 \pm 0.95 \times 1012 / /$ and leukopenia up to $97.3 \pm 12.21 \times 109 /$, The increase in BSR $(8.3 \pm 2.10 \mathrm{~mm} / \mathrm{h})$. During the analysis of biochemical parameters, the following changes were noted: the decrease in the level of total protein to $53.74 \pm 1.82 \mathrm{~g} / \mathrm{l}$; the decrease in the amount of albumin to $23.95 \pm 1.71 \mathrm{~g} / \mathrm{l}$, 
the increase in the activity of alanine aminotransferase to $123.81 \pm 11.58 \mathrm{U} / \mathrm{l}$ and alkaline phosphatase $93.54 \pm 12.77 \mathrm{U} / \mathrm{l}$, the increase in the level of urea to $7,43 \pm 1.18 \mathrm{mmol} / \mathrm{L}$.

2. In piglets with the clinical manifestation of the disease, the following hematological parameters were noted: the decrease in the number of red blood cells to $3.27 \pm 0.81$ $\times 1012 / \mathrm{l}$ and white blood cells to $9.15 \pm 3.33 \times 109 \mathrm{~g} / \mathrm{l}$, the increase in BSR to $13.22 \pm$ $3,44 \mathrm{~mm} / \mathrm{h}$, eosinopenia $2.48 \pm 0.46 \%$. During the analysis of biochemical parameters, hypoproteinemia was observed up to $48.6 \pm 1.97 \mathrm{~g} / \mathrm{l}$, hypoalbuminemia up to $17.88 \pm$ $3.04 \mathrm{~g} / \mathrm{l}$, hypoglobulinemia up to $30.52 \pm 5.57 \mathrm{~g} / \mathrm{l}$, the increase in urea level up to 10.52 $\pm 1.68 \mathrm{mmol} / \mathrm{L}$, the increase in the activity of alanine aminotransferase to $123.81 \pm 11.58$ $\mathrm{U} / \mathrm{L}$ and alkaline phosphatase to $166.9 \pm 11.76 \mathrm{U} / \mathrm{L}$, hyperglycemia $8.74 \pm 0.10 \mathrm{mmol} / \mathrm{L}$.

\section{References}

[1] Betlach, A. M., et al. (2019). Mycoplasma Hyopneumoniae Variability: Current Trends and Proposed Terminology for Genomic Transboundary and Emerging Diseases, vol. 66 , issue 5 , pp. 1840-54.

[2] Polishchuk, S. V. and Belyavtseva, E. A. (2015). Diagnosis Enzootic Pneumonia Pigs at Farm "Veles-Crimea". Transactions of Taurida Agricultural Science, vol. 1, issue 164, pp. 164-71.

[3] Thacker, E. L., Halbur, P. G. and Ross, R. F. (1999). Mycoplasma Hyopneumoniae Potentiation of Porcine Reproductive and Respiratory Syndrome Virus Induced Pneumonia. Journal of Clinical Microbiology, vol. 37, issue 3, pp. 620-7.

[4] Ayshpur, O. Y. (2014). Mycoplasmal (Enzootic) Pneumonia of Pigs. Animal Biology, vol. 16, issue 2, pp. 9-17.

[5] Butenkov, A. I., et al. (2009). Results Studying of Humoral and Cellular System of Immunity at Pigs with Enzootic Pneumonia. Veterinariya Kubani, vol. 3, pp. 13-5.

[6] Silva, G. S., et al. (2019). Benefit-cost Analysis to Estimate the Payback Time and the Economic Value of two Mycoplasma Hyopneumoniae Elimination Methods in Breeding Herds. Preventive Veterinary Medicine, vol. 168, pp. 95-102.

[7] Wang, H., et al. (2016). The Effects of Mycoplasma Hyopneumoniae on Porcine Circovirus Type 2 Replication in Vitro PK-15 Cells. Research in Veterinary Science, vol. 105 , pp. 56-61.

[8] Maes, D., et al. (2018). Update on Mycoplasma Hyopneumoniae Infections in Pigs: Knowledge Gaps for Improved Disease Control. Transboundary and Emerging Diseases vol. 65, issue 1, pp. 110-24. 
[9] Vicca, J., et al. (2003). Evaluation of Virulence Mycoplasma Hyopneumoniae Field Isolates. Veterinary Microbiology, vol. 97, pp. 177-90.

[10] Baborenko, Y. P. and Dolganova, Y. K. (2010). Mycoplasma Hyopneumoniae Serological Status of Pigs from Different Age Groups. Works of Federal Centre for Animal Health, vol. 8, issue 1, pp. 134-41.

[11] Tazayan, A. N., Tambiev, T. S. and Koshlyak, V. V. (2017). Peculiarities of Pigs' Enzootic Pneumonia Course. Actual Problems and Methodical Approaches to Diagnostics, Treatment and Prevention of Animal Diseases, vol. 2, pp. 154-157. 